\title{
O UNIVERSO DO TRABALHO EM O CORTIÇO DE ALUÍSIO AZEVEDO
}

\author{
Ângela Maria Rubel Fanini
}

\begin{abstract}
Resumo: Aluísio Azevedo, romancista do século XIX, retrata em sua obra inúmeros personagens trabalhadores, fazendo migrar para a esfera ficcional parte do mundo do trabalho oitocentista da sociedade carioca. Neste artigo, focaliza-se esse universo no romance $O$ Cortiço, analisando as múltiplas faces do trabalho, em virtude de classe social, gênero e etnia.
\end{abstract}

Palavras-chave: romance; século XIX; Aluísio Azevedo; universo do trabalho.

\section{LABOR UNIVERSE IN THE NOVEL O CORTIÇO BY ALUÍSIO AZEVEDO}

\begin{abstract}
Aluisio Azevedo, Brazilian novelist of the 19th century, depicts in his writings workers characters, formalizing in a certain extension the labour universe belonged to the Brazilian society in those times. In this paper, this literary setting is focused through the analyses of the novel $O$ Cortiço, studying the multiples faces of labour, due to social class, gender and ethnic issue.
\end{abstract}

Key-words: Brazilian novel; Aluísio Azevedo; labour universe.

\section{Introdução}

Candido (1981, p.117) argumenta que a obra de Aluísio Azevedo se afasta da realidade nacional uma vez que não se vincula à tradição literária interna, “empenhada e interessada” em retratar o local. Aproxima-se de uma dada estética francesa, transportando-a para o cenário nacional, sem contudo adaptá-la. Na década de 70, desloca essa análise (Candido, 1974, p.787-799), enfatizando em $O$ Cortiço a articulação com a história da acumulação primitiva de capital no Brasil, formalizada a partir do conflito entre personagens pobres e ricos. Segundo o crítico, a animalização que incide sobre as personagens de $O$ Cortiço é diferenciada e mediada pela categoria trabalho. Os que não trabalham em condições adversas, provinientes de estratos sociais elevados, são animalizados de forma branda. Já as personagens pobres trabalham em condições brutais e desumanas e são descritas de modo muito mais animalesco. 
Atendo-se a essa perspectiva que destaca a articulação da obra ao cenário nacional e em que a categoria trabalho assume relevância, este artigo procura verificar a representação literária das várias formas de trabalho (material, imaterial, escravo, assalariado) que ocorrem em O Cortiço e de como essa tipologia orienta o destino das personagens, dependendo de gênero, etnia e classe social.

O foco no trabalho enquanto representação estética se justifica uma vez que Aluísio Azevedo é um dos primeiros escritores a ficcionalizar as personagens secundárias e principais na labuta cotidiana, demonstrando que o universo laboral está presente no cenário literário. O destaque para o universo do trabalho se explica em virtude de que o campo literário, devido às novas configurações sociais na sociedade brasileira (Abolição da Escravatura, vinda dos emigrantes europeus e advento de uma classe média incipiente), passa a privilegiar a representação das classes labutadoras e mais humildes. Além disso, percebe-se que Aluísio Azevedo, por ter exercido várias profissões como caixeiro, vendedor de balcão e contabilista, apresenta-se sensível a uma diversidade de tipos laborais. Abandona essas atividades por lhe serem muito penosas e dedica-se, exclusivamente ao trabalho imaterial, tornando-se escritor. Entretanto, essa profissão é também descartada tão logo consegue um emprego público por volta dos 40 anos de idade. A partir desse momento, passa a ter melhores condições de vida material. Essa trajetória laboral diversificada pode também ter contribuído para a representação do trabalho em sua obra. Valentim Magalhães informa a vida parca que levava o escritor ao viver da literatura, asseverando: “é no Brasil talvez o único escritor que ganha o pão exclusivamente à custa de sua pena, mas note-se que ganha apenas o pão: as letras no Brasil ainda não dão para a manteiga.” (BOSI, 1984, p.210).

A fundamentação teórica neste artigo recorre, primeiramente, às considerações de Marx (1986) e Engels (1990) que evidenciaram em sua vasta obra a importância do trabalho coletivo como elemento fundador do ser social. Encontram-se em seus escritos tanto uma posição ontológica em que ocorre a passagem do animal ao ser social a partir do trabalho quanto uma posição histórica de investigação ampla do universo do trabalho em suas manifestações de alienação, expropriação e também de emancipação dentro da sociedade moderna fundada no modo de produção capitalista. A presente investigação aproxima-se também de Lukács (2004), que recuperando esses autores, apresenta uma posição similar em relação ao universo do trabalho, afirmando sua centralidade para a constituição do ser social, identificando a atividade laboral primeva à protogênese da práxis social. Para o pensador, o trabalho se constitui entre duas determinantes articuladas que denomina causalidade e teleologia, destacando tanto o reino da necessidade quanto o da liberdade no âmbito do trabalho. 
Também recorre-se a Marcuse (1992), em que ocorre uma visão positiva sobre o trabalho, distanciando-se de uma perspectiva somente punitiva e castradora que, não raras vezes ocorre em discursos sobre o trabalho. O autor, dialogando diretamente com Freud, argumenta que a atividade laboral pode concretizar-se a partir do princípio do prazer, à medida que pode fundar-se em uma atividade não alienada, libertando-se de um fim puramente instrumental cujos objetivos se reduzam à aquisição de bens de consumo. Vê-se aí, por intermédio de um trabalho coletivo, produtivo e ontologicamente fundante, uma possível conjugação entre princípio da realidade e princípio do prazer, possibilitando antes a interação entre “eros” e “civilização” do que sua irremediável separação. Finalmente, incorpora-se o pensamento de Antunes (2002 ), que segue essa tradição de pensamento, enfatizando a centralidade do trabalho, mesmo no período atual, em que inúmeros autores negam essa dimensão central, destacando um mundo pós-trabalho. Para o autor, o trabalho continua a ser uma categoria de fundamento para o ser social e, em tendo sentido humanizador e emancipatório, confere sentido também à vida e práxis cotidianas.

A análise vincula-se à linha de pesquisa denominada Trabalho, Tecnologia e Cultura em que se investigam as representações discursivas desses três âmbitos nos produtos culturais.

\section{A centralidade do trabalho no destino e vida das personagens}

A trajetória da personagem João Romão “reflete e refrata” (BAKHTIN, 1986) a vida do português pobre que emigra de Portugal para a colônia em busca de ascensão econômica. A personagem passa de auxiliar de vendas em uma quitanda a Visconde, por intermédio de poupança árdua, trabalho brutal, expropriação do trabalho dos mineiros que labutam em sua pedreira, dos inquilinos do cortiço de sua propriedade e do trabalho escravo.

A passagem de classe social é descrita a partir de uma mudança de comportamento lenta, radical e penosa. João Romão, já detentor de poder econômico, vê a necessidade de adquirir a cultura e os valores das classes abastadas. Deseja e consegue o título de Visconde que lhe confere status simbólico e cultural, agregado ao poder material conquistado no trabalho e na expropriação do outro e dos bens de outrem. Essa articulação do valor econômico ao simbólico lembra a transição das classes burguesas em outras nações no século XIX, a quem só o poder econômico não satisfazia, almejando o poder político-social. Percebe-se a angústia psicológica de que padece ao ver-se de outra classe e a metamorfose em busca da tão desejava mobilidade: 
E, caso resolvesse mudar de vida radicalmente, unir-se a uma senhora bem-educada e distinta de maneiras, montar um sobrado como o do Miranda e volver-se titular, estaria apto para o fazer?... Poderia dar conta do recado?... Dependeria tudo isso somente de sua vontade?... Com aqueles pés, deformados pelo diabo dos tamancos, criados à solta, sem meias, como calçaria sapatos de baile?... E suas mãos, calosas e maltratadas, duras como as de um cavouqueiro, como se ajeitariam com a luva'... E isso não era tudo! O mais difícil seria o que tivesse de dizer aos seus convidados! Como deveria tratar as damas e cavalheiros, em meio de um grande salão cheio de espelhos e cadeiras douradas? ... Como se arranjaria, sem dizer barbaridades?(p.169)

Percebe-se a articulação entre o trabalho material e a ascensão econômica, pois sua riqueza vem tanto da labuta cotidiana quanto da exploração do outro. O sentido dessa labuta é único, ou seja, poupar, enriquecer e acumular. Não há espaço e tempo para o ócio e o prazer. Entretanto, ao concretizar esse fim, vê-se embrutecido pelo processo cego de enriquecer a qualquer custo. Deseja alterar a sua condição e dar outro sentido a sua existência. Na almejada alteração de classe social, ocorre uma desarticulação entre trabalho e sentido da existência, pois o trabalho material que exercia é derrogatório no novo horizonte de classe. Ao final da narrativa, a personagem já não exerce nenhuma atividade laboral material, apenas gerenciando o trabalho dos outros, transformando-se em um grande investidor financeiro. O trabalho material tanto de exploração ferrenha de si quanto dos outros fornece a base para a sua riqueza, mas já não pode ser exercido por ele à medida que ocupa outra função social, obrigando-se a novos comportamentos em que a civilidade, a sofisticação, a polidez o impedem de se imiscuir no degradante universo material a que estava vinculado.

Em relação ao trabalho escravo, tem-se a sua representação na personagem Bertoleza que, mesmo na condição de escrava, apresenta comportamento não totalmente submisso, mas muitas vezes insurrecto à medida que é escrava fugida, vive na condição de trabalhadora assalariada e, ao final, ao saber que será devolvida ao cativeiro, suicida-se como forma de libertação. Bertoleza representa o escravo parcialmente autodeterminado, com certo poder de negociação, desviando-se parcialmente da imagem do escravo objeto, alienado e passivo ao cativeiro. A perspectiva do escravo reificado é dada em Gorender (1992). Já a visão da negociação e do escravo sujeito é dada em Chalhoub (1990). Assumimos que Bertoleza é formalizada tanto como sujeito quanto objeto no mundo do trabalho. Na condição de escrava fugida, trabalha na cidade para um quituteiro, percebendo salário, já denotando uma condição de autodeterminação. Ao conhecer João Romão, abandona o vendeiro e passa a trabalhar para ele e é também sua concubina. O companheiro tomalhe as economias e forja uma carta de alforria, ludibriando-a. Ilusoriamente vive uma existência livre.Todo trabalho tem um único fim, ou seja, acumular e enriquecer, vivendo em condições frugais extremas. Por sua condição ambígua entre sujeito de sua trajetória e objeto dos desígneos de 
outrem, insurge-se contra essa desdita. Bertoleza expressa voz, vontade e desejo de vingança em relação à expropriação no âmbito de gênero e do trabalho de que fora vítima de João Romão:

\begin{abstract}
Você está muito enganado, 'seu’ João, se cuida que se casa e me atira à toa! Exclamou ela. Sou negra, sim, mas tenho sentimentos! Quem me comeu a carne tem de roer-me os ossos! Então há de uma criatura ver entrar e sair ano a puxar pelo corpo todo o santo dia que Deus manda ao mundo, desde pela manhãzinha até pelas tantas da noite, para depois ser jogada no meio da rua, como galinha podre?! Não! não há de ser assim, 'seu 'João'. (p.333)
\end{abstract}

Entretanto essa margem de negociação é pequena e o sistema escravista a aniquila, revelando-se escravo objeto, expropriado e explorado em sua labuta cotidiana em prol da ascensão sócio-econômica dos proprietários.

Ao final da narrativa, João Romão casa-se com moça da alta sociedade. Para atingir esse fim, tenta devolver Bertoleza ao seu verdadeiro proprietário. À medida que João Romão migra de classe, precisa se "civilizar", adquirindo outros valores e cultura. Urge se desvencilhar de seu passado escravista, escamoteando o acúmulo selvagem e desumano de capital. Bertoleza deve ser aniquilada, pois representa essa trajetória. O trabalho submetido à árdua poupança e fonte de privação deve ser suprimido da memória, pois vincula-se à atividade escrava e não nobre, visão típica da sociedade brasileira oitocentista cuja economia escravista percebe o trabalho material como derrogatório.

Bertoleza devia ser esmagada, devia ser suprimida, porque era tudo que havia de mau na vida dele! (...) Ela era o torpe balcão da primitiva bodega; era o aladroado vintenzinho de manteiga em papel pardo; era o peixe trazido da praia e vendido à noite ao lado do fogareiro à porta da taberna; era o frege imundo e a lista cantada das comezainas à portuguesa; era o sono roncado no colchão fétido, cheio de bichos; ela era a sua cúmplice e era todo o seu mal - devia, pois extinguir-se. Devia ceder lugar à pálida mocinha de mãos delicadas e cabelos perfumados, que era o bem, poque era o que ria e alegrava, porque era vida nova, o romance solfejado ao piano, as flores nas jarras, as sedas, as rendas, o chá servido em porcelanas caras; era enfim a doce existência dos ricos, dos felizes e dos fortes, dos que herdaram sem trabalho ou dos que, a puro esforço, conseguiram acumular dinheiro, rompendo e subindo por entre o rebanho dos escrupulosos ou dos fracos. (p.324)

O trabalho material é demonstrado pelo labor coletivo nas pedreiras em que se lembra simbolicamente o inferno onde os homens lutam sisefianamente contra o trabalho que os subsume. A luta contra a pedreira é inglória, demonstrando o homem na tentativa de modificar a natureza, supliciando o corpo. Esse trabalho é alienante uma vez que é desprovido de autodeterminação. É determinado de fora, sob a direção e supervisão de inspetores e o resultado é apropriado pelo proprietário da pedreira. O trabalho é direcionado sob perspectiva de fora e para fora é deslocado, atendendo à maximização das horas trabalhadas e do lucro. 
A vida dos trabalhadores, apesar de penosa, é interrompida para vivenciarem atividades de entretenimento, revelando-se a vida coletiva e privada dos trabalhadores fora da labuta cotidiana. Ocorre uma disjunção entre trabalho e vida, pois aquele é estafante e expropriado:

\begin{abstract}
Amanhecera um domingo alegre no cortiço. (...) As tinas estavam abandonadas; os coradouros despidos. Tabuleiros e tabuleiros de roupa engomada saíam das casinhas, carregados na maior parte pelos filhos das próprias lavadeiras que se mostravam agora quase todas de fato limpo; os casaquinhos brancos avultavam por cima da saias de chita de cor.(...) Viam-se homens de corpo nu, jogando a placa, com grande algazarra. Um grupo de italianos, assentado debaixo de uma árvore, conversava ruidosamnete, fumando caximbo. À porta de diversos cômodos, trabalhadores descansavam, de calça limpa e camisa de meia lavada, assentados nas cadeiras, lendo e soletrando jornais e livros; um declamava em voz alta versos de Os Lusíadas, com um empenho feroz que o punha rouco. Transparecia neles o prazer da roupa mudada depois de uma semana no corpo. (p.82)
\end{abstract}

A personagem Jerônimo é português e vem para a colônia trabalhar com o fito de melhorar de vida. A sua trajetória é oposta a de João Romão. Primeiramente, não se estabelece no comércio como é o caso deste. Nesse sentido não é negociante e não aufere lucros de intermediação de bens. Em segundo lugar, encarna uma ética positiva do trabalho, crendo que se dignifica a partir do trabalho sério, comprometido e autodeterminado. Sua queda, no entanto, pode ser interpretada no sentido de que, em não expropriando o trabalho alheio, não ascede como ocorre com João Romão. Outra justificativa para sua queda é ter-se envolvido com a personagem Rita Baiana e se desviado do paradigma do trabalho, preferindo o ócio. Tem-se a imagem inicial de Jerônimo, antes da queda, revelando um trabalhador gerente, hierarquicamente superior em termos de capacidade técnica em relação aos demais.

O universo do trabalho versus o ócio é representado na figura de Rita Baiana que pode simbolizar, a partir das lentes deterministas de caráter mesológico e de mestiçagem, a inviabilidade do trabalho racional, metódico e sistemático à medida que se associa ao universo tropical que constitui, em parte, segundo Aluísio Azevedo, a identidade nacional. Essa visão determinista resulta da utilização de idéias eurocêntricas para ler a realidade nacional. A postura de Aluísio é chamada por Sodré (1984) de “ideologia do colonialismo” que atinge outros escritores do século XIX como José de Alencar e Silvio Romero. A partir desse conjunto de idéias se vincula a inferioridade do brasileiro ao fenômeno da mestiçagem. Na obra em tela, a personagem Rita Baiana é apresentada por intermédio de certa perspectiva eurocêntrica que a faz voltar-se, sobretudo para o ócio. O maior objetivo do trabalho cotidiano da personagem é antes financiar as festas que promove no espaço do cortiço do que sobreviver materialmente e acumular. O ócio sobrevém o trabalho. Aluísio, reafirmando a inferioridade da mestiçagem, traz à luz a queda da personagem Jerônimo, que embora 
se vincule ao trabalho burguês, ao se amasiar com Rita Baiana, desnorteia-se, tornando-se ocioso. No excerto a seguir, reforçando-se essa dicotomia entre trabalho e lazer, o romancista destaca a especificidade da cultura nacional, a partir de sua matriz indígena, que resiste à imposição do trabalho burguês:

\begin{abstract}
A vida americana e a natureza do Brasil patenteavam-lhe agora aspectos imprevistos e sedutores que o comoviam; esquecia-se dos seus primitivos sonhos e ambição, para idealizar felicidades novas, picantes e violentas; tornava-se liberal, imprevidente e franco, mais amigo de gastar que de guardar: adquiria desejos, tomava gosto aos prazeres, e volvia-se preguiçoso resignando-se, vencido, às imposições do sol e do calor, muralha de fogo que o espírito eternamente revoltado do último tamoio entrincheirou a pátria contra os conquistadores aventureiros.(p. 132)
\end{abstract}

O universo do não trabalho é focalizado pela personagem Botelho (rico decadente, sem funcionalidade, vivendo de favor) que representa o universo de clientelismo vigente na sociedade oitocentista. Consultar Schwarz (2000) e Franco (1997), para quem a economia escravista oitocentista, em virtude de que o trabalho é majoritariamente exercido por escravos, gera uma sociedade baseada no favor para a maioria dos pobres livres em que os agregados polulam nas casas e nas fazendas.

O espaço do cortiço é o local de moradia dos trabalhadores das classes não abastadas em contraposição ao espaço burguês que predomina no sobrado contíguo de propriedade da personagem Barão Miranda. O cortiço inicial, denominado “Estalagem São Romão”, de propriedade de João Romão, é abrigado por trabalhadores bastante pobres. É destruído por um incêndio criminoso. Ao ser reconstruído, sob a denominação “Avenida São Romão”, outra classe de trabalhadores ali é alojada. A alteração representa uma complexificação social, emergindo e ampliando-se as classes-médias, pois entre os novos moradores há estudantes, contínuos de repartições públicas, caixeiros de botequim, artistas de teatro, condutores de bonde, vendedores de loteria, alfaiates, relojoeiros, pintores, cigarreiros. A continuidade das classes mais desfavorecidas se perpetua em outro cortiço de pior qualidade, denominado “Cabeça de Gato”. Isso representa o surgimento de outra classe social que "aristocratiza” o novo cortiço e a permanência do trabalhador mais pobre que migra para o cortiço mais abjeto. As estratificações sociais se complexificam na sociedade oitocentista, sobretudo com a alteração do regime escravista e a chegada dos imigrantes europeus.

A centralidade do trabalho na obra é evidente à medida que inúmeras personagens são figuradas na faina diária, sem contudo, perderem sua individualidade. O escritor desenvolve uma narrativa para cada uma, dotada de dramas próprios. As personagens lavadeiras são em grande 
número e algumas recebem tratamento ficcional que simultaneamente as representa como uma totalidade, constituídas por uma certa visão de classe uma vez que exercem atividades muito semelhantes. Entretanto, dota-as de destinos e competências diferentes além do trabalho. O trabalho, talvez por não ser fabril e por seu caráter artesanal, é exercido de forma parcialmente determinado. Parece não objetificar as lavadeiras que o exercem com alegria, tendo orgulho pelo produto final. O método que utilizam para lavar as roupas para as classes abastadas é o mesmo empregado para lavar as suas prórpias vestimentas.Talvez aí resida a não alienação no trabalho e esse é representado de modo prazeroso. Outro ponto que reforça o sentido humano desse trabalho é a sua parcial autodeterminação uma vez que as lavadeiras alugam água, tina e demais produtos, gerenciando parte do processo e não estão condicionadas à inspeção de fora. Há certa autonomia do processo, podendo ser subjetivado.

\section{Considerações finais}

O universo do trabalho apresenta-se formalizado no romance $O$ Cortiço, sendo focalizado em suas múltiplas facetas: trabalho escravo como base de sustentação da aristocracia urbana e já em decadência à medida que novos paradigmas adentram a sociedade oitocentista; trabalho assalariado como forma de sobrevivência material, mas em condições precárias visto que representativo de uma fase de extrema expropriação do trabalhador livre; trabalho como forma de ascensão social associado à expropriação do outro; trabalho contraposto ao ócio, representando as diferenças deterministas mesológicas e raciais; tendo-se a realidade tropical e da mestiçagem como avessa ao trabalho metódico, sistemático, ordenado e parcialmente autodetermindo. Finalmente tem-se a representação de uma gama de trabalhadores livres e profissionais liberais que vivem do trabalho, apontando para a ascensão de classes médias, modificando a estratificação social oitocentista. O universo do não trabalho também é representado na figura do agregado que aponta para uma sociedade escravista e agro-exportadora onde há escassez de postos de trabalho, fazendo com que muitos tenham que depender do favor das classes abastadas para subsistirem.

\section{Referências}

ANTUNES, Ricardo. Os sentidos do trabalho: ensaio sobre a afirmação e a negação do trabalho. 6. ed. São Paulo: Boitempo, 2002.

AZEVEDO, Azevedo. O cortiço. Rio de Janeiro: Otto Pierre Editores, 1979. 
BAKHTIN, Mikhail. Marxismo e Filosofia da linguagem. Trad. Michel Lahud e Yara Frateschi Vieira. São Paulo: Hucitec, 1986.

BOSI, Alfredo. História concisa da literatura brasileira. 3. ed. São Paulo: Cultrix, 1984.

CANDIDO, Antonio. Formação da Literatura Brasileira (Movimentos decisivos). 6. ed. v.2. Belo Horizonte: Ed. Itatiaia, 1981.

. A passagem do dois ao três (contribuição para o estudo das mediações na análise literária). In: Revista de História. Ano 25, tomo 3, v. 50, número 100, São Paulo, out/dez, 1974, p.787-799.

CHALHOUB, Sidney. Visões da liberdade: uma história das últimas décadas da escravidão. São Paulo: Companhia das Letras, 1999.

ENGELS, Friedrich. O papel do trabalho na transformação do macaco em homem. 4. ed. Rio de Janeiro: Global, 1990.

MARCUSE, Herbert. Eros e Civilização: Uma Interpretação Filosófica do Pensamento de Freud. Trad. Álvaro Cabral. $8^{\circ}$ ed. Rio de Janeiro: Zahar,1992.

MARX, Karl. A Maquinaria e a Indústria Moderna. In: O Capital: Crítica da Economia Política. Trad. Reginaldo Santanna. $12^{\circ}$ ed. Rio de Janeiro: Bertrand, 1986.

FRANCO, Maria Sylvia. de Mello. C. Homens livres na ordem escravocrata. 4. ed. São Paulo: Unesp, 1997.

GORENDER, Jacob. O escravismo colonial. São Paulo: Ática, 1992. . A escravidão reabilitada. São Paulo: Ática, 1990.

LUKÁCS, Georg. Ontologia del ser social: el trabajo.Buenos Aires: Herramienta, 2004.

SODRE, Nelson Werneck. Ideologia do colonialismo: seus reflexos no pensamento brasileiro.3.ed. Petrópolis: Vozes, 1984.

SCHWARZ, Roberto. As idéias fora do lugar. In: Ao vencedor as batatas: forma literária e processo social nos inícios do romance brasileiro. 34. ed. São Paulo: Duas Cidades, 2000.

WEBER, João Hernesto. Caminhos do romance brasileiro: de A Moreninha a Os Guaianãs. Porto Alegre: Mercado Aberto, 1990. 